\title{
Approximation of Common Fixed Points of a Countable Family of Relatively Nonexpansive Mappings
}

\author{
Daruni Boonchari ${ }^{1}$ and Satit Saejung ${ }^{2}$ \\ ${ }^{1}$ Department of Mathematics, Mahasarakham University, Maha Sarakham 44150, Thailand \\ ${ }^{2}$ Department of Mathematics, Khon Kaen University, Khon Kaen 40002, Thailand
}

Correspondence should be addressed to Satit Saejung, saejung@kku.ac.th

Received 22 June 2009; Revised 20 October 2009; Accepted 21 November 2009

Academic Editor: Tomonari Suzuki

Copyright (C) 2010 D. Boonchari and S. Saejung. This is an open access article distributed under the Creative Commons Attribution License, which permits unrestricted use, distribution, and reproduction in any medium, provided the original work is properly cited.

We introduce two general iterative schemes for finding a common fixed point of a countable family of relatively nonexpansive mappings in a Banach space. Under suitable setting, we not only obtain several convergence theorems announced by many authors but also prove them under weaker assumptions. Applications to the problem of finding a common element of the fixed point set of a relatively nonexpansive mapping and the solution set of an equilibrium problem are also discussed.

\section{Introduction and Preliminaries}

Let $C$ be a nonempty subset of a Banach space $E$, and let $T$ be a mapping from $C$ into itself. When $\left\{x_{n}\right\}$ is a sequence in $E$, we denote strong convergence of $\left\{x_{n}\right\}$ to $x \in E$ by $x_{n} \rightarrow x$ and weak convergence by $x_{n} \rightarrow x$. We also denote the weak ${ }^{*}$ convergence of a sequence $\left\{x_{n}^{*}\right\}$ to $x^{*}$ in the dual $E^{*}$ by $x_{n}^{*} \stackrel{*}{\rightarrow} x^{*}$. A point $p \in C$ is an asymptotic fixed point of $T$ if there exists $\left\{x_{n}\right\}$ in $C$ such that $x_{n} \rightarrow p$ and $x_{n}-T x_{n} \rightarrow 0$. We denote $F(T)$ and $\widehat{F}(T)$ by the set of fixed points and of asymptotic fixed points of $T$, respectively. A Banach space $E$ is said to be strictly convex if $\|x+y\| / 2<1$ for $x, y \in S(E)=\{z \in E:\|z\|=1\}$ and $x \neq y$. It is also said to be uniformly convex if for each $\epsilon \in(0,2]$, there exists $\delta>0$ such that $\|x+y\| / 2<1-\delta$ for $x, y \in S(E)$ and $\|x-y\| \geq \epsilon$. The space $E$ is said to be smooth if the limit

$$
\lim _{t \rightarrow 0} \frac{\|x+t x\|-\|x\|}{t}
$$


exists for all $x, y \in S(E)$. It is also said to be uniformly smooth if the limit exists uniformly in $x, y \in S(E)$.

Many problems in nonlinear analysis can be formulated as a problem of finding a fixed point of a certain mapping or a common fixed point of a family of mappings. This paper deals with a class of nonlinear mappings, so-called relatively nonexpansive mappings introduced by Matsushita and Takahashi [1]. This type of mappings is closely related to the resolvent of maximal monotone operators (see [2-4]).

Let $E$ be a smooth, strictly convex and reflexive Banach space and let $C$ be a nonempty closed convex subset of $E$. Throughout this paper, we denote by $\phi$ the function defined by

$$
\phi(x, y)=\|x\|^{2}-2\langle x, J y\rangle+\|y\|^{2} \quad \forall x, y \in E,
$$

where $J$ is the normalized duality mapping from $E$ to the dual space $E^{*}$ given by the following relation:

$$
\langle x, J x\rangle=\|x\|^{2}=\|J x\|^{2} .
$$

We know that if $E$ is smooth, strictly convex, and reflexive, then the duality mapping $J$ is single-valued, one-to-one, and onto. The duality mapping $J$ is said to be weakly sequentially continuous if $x_{n} \rightarrow x$ implies that $J x_{n} \stackrel{*}{\rightarrow} J x$ (see [5] for more details).

Following Matsushita and Takahashi [6], a mapping $T: C \rightarrow E$ is said to be relatively nonexpansive if the following conditions are satisfied:

(R1) $F(T)$ is nonempty;

(R2) $\phi(u, T x) \leq \phi(u, x)$ for all $u \in F(T), x \in C$;

(R3) $\widehat{F}(T)=F(T)$.

If $T$ satisfies (R1) and (R2), then $T$ is called relatively quasi-nonexpansive [7]. Obviously, relative nonexpansiveness implies relative quasi-nonexpansiveness but the converse is not true. Relatively quasi-nonexpansive mappings are sometimes called hemirelatively nonexpansive mappings. But we do prefer the former name because in a Hilbert space setting, relatively quasi-nonexpansive mappings are nothing but quasi-nonexpansive.

In [2], Alber introduced the generalized projection $\Pi_{C}$ from $E$ onto $C$ as follows:

$$
\Pi_{C}(x)=\arg \min _{y \in C} \phi(y, x) \quad \forall x \in E
$$

If $E$ is a Hilbert space, then $\phi(y, x)=\|y-x\|^{2}$ and $\Pi_{C}$ becomes the metric projection of $E$ onto $C$. Alber's generalized projection is an example of relatively nonexpansive mappings. For more example, see $[1,8]$.

In 2004, Masushita and Takahashi [1, 6] also proved weak and strong convergence theorems for finding a fixed point of a single relatively nonexpansive mapping. Several iterative methods, as a generalization of $[1,6]$, for finding a common fixed point of the family of relatively nonexpansive mappings have been further studied in $[7,9-14]$. 
Recently, a problem of finding a common element of the set of solutions of an equilibrium problem and the set of fixed points of a relatively nonexpansive mapping is studied by Takahashi and Zembayashi in $[15,16]$. The purpose of this paper is to introduce a new iterative scheme which unifies several ones studied by many authors and to deduce the corresponding convergence theorems under the weaker assumptions. More precisely, many restrictions as were the case in other papers are dropped away.

First, we start with some preliminaries which will be used throughout the paper.

Lemma 1.1 (see [7, Lemma 2.5]). Let $C$ be a nonempty closed convex subset of a strictly convex and smooth Banach space $E$ and let $T$ be a relatively quasi-nonexpansive mapping from $C$ into itself. Then $F(T)$ is closed and convex.

Lemma 1.2 (see [17, Proposition 5]). Let C be a nonempty closed convex subset of a smooth, strictly convex, and reflexive Banach space E. Then

$$
\phi\left(x, \Pi_{C} y\right)+\phi\left(\Pi_{C} y, y\right) \leq \phi(x, y)
$$

for all $x \in C$ and $y \in E$.

Lemma 1.3 (see [17]). Let E be a smooth and uniformly convex Banach space and let $r>0$. Then there exists a strictly increasing, continuous, and convex function $h:[0,2 r] \rightarrow \mathbb{R}$ such that $h(0)=0$ and

$$
h(\|x-y\|) \leq \phi(x, y)
$$

for all $x, y \in B_{r}=\{z \in E:\|z\| \leq r\}$.

Lemma 1.4 (see [17, Proposition 2]). Let E be a smooth and uniformly convex Banach space and let $\left\{x_{n}\right\}$ and $\left\{y_{n}\right\}$ be sequences of $E$ such that either $\left\{x_{n}\right\}$ or $\left\{y_{n}\right\}$ is bounded. If $\lim _{n \rightarrow \infty} \phi\left(x_{n}, y_{n}\right)=0$, then $\lim _{n \rightarrow \infty}\left\|x_{n}-y_{n}\right\|=0$.

Lemma 1.5 (see [2]). Let $C$ be a nonempty closed convex subset of a smooth, strictly convex, and reflexive Banach space $E$, let $x \in E$, and let $z \in C$. Then

$$
z=\Pi_{C} x \Longleftrightarrow\langle y-z, J x-J z\rangle \leq 0, \quad \forall y \in C
$$

Lemma 1.6 (see [18]). Let E be a uniformly convex Banach space and let $r>0$. Then there exists a strictly increasing, continuous, and convex function $g:[0,2 r] \rightarrow \mathbb{R}$ such that $g(0)=0$ and

$$
\|t x+(1-t) y\|^{2} \leq t\|x\|^{2}+(1-t)\|y\|^{2}-t(1-t) g(\|x-y\|)
$$

for all $x, y \in B_{r}$ and $t \in[0,1]$.

We next prove the following three lemmas which are very useful for our main results. 
Lemma 1.7. Let Let $C$ be a closed convex subset of a smooth Banach space $E$. Let $T$ be a relatively quasi-nonexpansive mapping from $E$ into $E$ and let $\left\{S_{i}\right\}_{i=1}^{N}$ be a family of relatively quasi-nonexpansive mappings from $C$ into itself such that $F(T) \cap \bigcap_{i=1}^{N} F\left(S_{i}\right) \neq \emptyset$. The mapping $U: C \rightarrow E$ is defined by

$$
U x=T J^{-1} \sum_{i=1}^{N} \omega_{i}\left(\alpha_{i} J x+\left(1-\alpha_{i}\right) J S_{i} x\right)
$$

for all $x \in C$ and $\left\{\omega_{i}\right\},\left\{\alpha_{i}\right\} \subset[0,1], i=1,2, \ldots, N$ such that $\sum_{i=1}^{N} \omega_{i}=1$. If $x \in C$ and $z \in$ $F(T) \cap \bigcap_{i=1}^{N} F\left(S_{i}\right)$, then

$$
\phi(z, U x) \leq \phi(z, x)
$$

Proof. The proof of this lemma can be extracted from that of Lemma 1.8; so it is omitted.

If $E$ has a stronger assumption, we have the following lemma.

Lemma 1.8. Let $C$ be a closed convex subset of a uniformly smooth Banach space E. Let $r>0$. Then, there exists a strictly increasing, continuous, and convex function $g^{*}:[0,6 r] \rightarrow \mathbb{R}$ such that $g^{*}(0)=0$ and for each relatively quasi-nonexpansive mapping $T: E \rightarrow E$ and each finite family of relatively quasi-nonexpansive mappings $\left\{S_{i}\right\}_{i=1}^{N}: C \rightarrow C$ such that $F(T) \cap \bigcap_{i=1}^{N} F\left(S_{i}\right) \neq \emptyset$,

$$
\sum_{i=1}^{N} \omega_{i} \alpha_{i}\left(1-\alpha_{i}\right) g^{*}\left(\left\|J z-J S_{i} z\right\|\right) \leq \phi(u, z)-\phi(u, U z)
$$

for all $z \in C \cap B_{r}$ and $u \in F(T) \cap \bigcap_{i=1}^{N} F\left(S_{i}\right) \cap B_{r}$, where

$$
U x=T J^{-1} \sum_{i=1}^{N} \omega_{i}\left(\alpha_{i} J x+\left(1-\alpha_{i}\right) J S_{i} x\right)
$$

$x \in C$ and $\left\{\omega_{i}\right\},\left\{\alpha_{i}\right\} \subset[0,1], i=1,2, \ldots, N$ such that $\sum_{i=1}^{N} \omega_{i}=1$.

Proof. Let $r>0$. From Lemma 1.6 and $E^{*}$ is uniformly convex, then there exists a strictly increasing, continuous, and convex function $g^{*}:[0,6 r] \rightarrow \mathbb{R}$ such that $g^{*}(0)=0$ and

$$
\left\|t x^{*}+(1-t) y^{*}\right\|^{2} \leq t\left\|x^{*}\right\|^{2}+(1-t)\left\|y^{*}\right\|^{2}-t(1-t) g^{*}\left(\left\|x^{*}-y^{*}\right\|\right)
$$

for all $x^{*}, y^{*} \in\left\{z^{*} \in E^{*}:\left\|z^{*}\right\| \leq 3 r\right\}$ and $t \in[0,1]$. Let $T: E \rightarrow E$ and $\left\{S_{i}\right\}_{i=1}^{N}: C \rightarrow C$ be relatively quasi-nonexpansive for all $i=1,2, \ldots, N$ such that $F(T) \cap \bigcap_{i=1}^{N} F\left(S_{i}\right) \neq \emptyset$. For $z \in C \cap B_{r}$ and $u \in F(T) \cap \bigcap_{i=1}^{N} F\left(S_{i}\right) \cap B_{r}$. It follows that

$$
\left(\|u\|-\left\|S_{i} z\right\|\right)^{2} \leq \phi\left(u, S_{i} z\right) \leq \phi(u, z) \leq(\|u\|+\|z\|)^{2} \leq(2 r)^{2}
$$


and hence $\left\|S_{i} z\right\| \leq 3 r$. Consequently, for $i=1,2, \ldots, N$,

$$
\left\|\alpha_{i} J z+\left(1-\alpha_{i}\right) J S_{i} z\right\|^{2} \leq \alpha_{i}\|J z\|^{2}+\left(1-\alpha_{i}\right)\left\|J S_{i} z\right\|^{2}-\alpha_{i}\left(1-\alpha_{i}\right) g^{*}\left(\left\|J z-J S_{i} z\right\|\right) .
$$

Then

$$
\begin{aligned}
\phi(u, U z) & \leq \phi\left(u, J^{-1} \sum_{i=1}^{N} \omega_{i}\left(\alpha_{i} J z+\left(1-\alpha_{i}\right) J S_{i} z\right)\right) \\
& =\|u\|^{2}-2\left\langle u, \sum_{i=1}^{N} \omega_{i}\left(\alpha_{i} J z+\left(1-\alpha_{i}\right) J S_{i} z\right)\right\rangle+\left\|\sum_{i=1}^{N} \omega_{i}\left(\alpha_{i} J z+\left(1-\alpha_{i}\right) J S_{i} z\right)\right\|^{2} \\
& \leq \sum_{i=1}^{N} \omega_{i}\left(\|u\|^{2}-2\left\langle u, \alpha_{i} J z+\left(1-\alpha_{i}\right) J S_{i} z\right\rangle+\left\|\alpha_{i} J z+\left(1-\alpha_{i}\right) J S_{i} z\right\|^{2}\right) \\
& \leq \sum_{i=1}^{N} \omega_{i}\left(\|u\|^{2}-2\left\langle u, \alpha_{i} J z+\left(1-\alpha_{i}\right) J S_{i} z\right\rangle+\alpha_{i}\|J z\|^{2}+\left(1-\alpha_{i}\right)\left\|J S_{i} z\right\|^{2}\right. \\
& \left.\quad-\alpha_{i}\left(1-\alpha_{i}\right) g^{*}\left(\left\|J z-J S_{i} z\right\|\right)\right) \\
& \leq \phi(u, z)-\sum_{i=1}^{N} \omega_{i} \alpha_{i}\left(1-\alpha_{i} \phi(u, z)+\left(1-\alpha_{i}\right) \phi\left(u, S_{i} z\right)-\alpha_{i}\left(1-\alpha_{i}\right) g^{*}\left(\left\|J z-J S_{i} z\right\|\right)\right)
\end{aligned}
$$

Thus

$$
\sum_{i=1}^{N} \omega_{i} \alpha_{i}\left(1-\alpha_{i}\right) g^{*}\left(\left\|J z-J S_{i} z\right\|\right) \leq \phi(u, z)-\phi(u, U z)
$$

Lemma 1.9. Let $C$ be a closed convex subset of a uniformly smooth and strictly convex Banach space $E$. Let $T$ be a relatively quasi-nonexpansive mapping from $E$ into $E$ and let $\left\{S_{i}\right\}_{i=1}^{N}$ be a family of relatively quasi-nonexpansive mappings from $C$ into itself such that $F(T) \cap \bigcap_{i=1}^{N} F\left(S_{i}\right) \neq \emptyset$. The mapping $U: C \rightarrow E$ is defined by

$$
U x=T J^{-1} \sum_{i=1}^{N} \omega_{i}\left(\alpha_{i} J x+\left(1-\alpha_{i}\right) J S_{i} x\right)
$$

for all $x \in C$ and $\left\{\omega_{i}\right\},\left\{\alpha_{i}\right\} \subset(0,1), i=1,2, \ldots, N$ such that $\sum_{i=1}^{N} \omega_{i}=1$. Then, the following hold:

(1) $F(U)=F(T) \cap \bigcap_{i=1}^{N} F\left(S_{i}\right)$,

(2) $U$ is relatively quasi-nonexpansive. 
Proof. (1) Clearly, $F(T) \cap \bigcap_{i=1}^{N} F\left(S_{i}\right) \subset F(U)$. We want to show the reverse inclusion. Let $z \in$ $F(U)$ and $u \in F(T) \cap \bigcap_{i=1}^{N} F\left(S_{i}\right)$. Choose

$$
r:=\max \left\{\|u\|,\|z\|,\left\|S_{1} z\right\|,\left\|S_{2} z\right\|, \ldots,\left\|S_{m} z\right\|\right\} .
$$

From Lemma 1.8, we have

$$
\sum_{i=1}^{N} \omega_{i} \alpha_{i}\left(1-\alpha_{i}\right) g^{*}\left(\left\|J z-J S_{i} z\right\|\right)=0
$$

From $\omega_{i} \alpha_{i}\left(1-\alpha_{i}\right)>0$ for all $i=1,2, \ldots, N$ and by the properties of $g^{*}$, we have

$$
J z=J S_{i} z
$$

for all $i=1,2, \ldots, N$. From $J$ is one to one, we have

$$
z=S_{i} z
$$

for all $i=1,2, \ldots, N$. Consider

$$
z=U z=T J^{-1} \sum_{i=1}^{N} \omega_{i}\left(\alpha_{i} J z+\left(1-\alpha_{i}\right) J S_{i} z\right)=T z
$$

Thus $z \in F(T) \cap \bigcap_{i=1}^{N} F\left(S_{i}\right)$.

(2) It follows directly from the above discussion.

\section{Weak Convergence Theorem}

Theorem 2.1. Let $C$ be a nonempty closed convex subset of a uniformly smooth and uniformly convex Banach space $E$. Let $\left\{T_{n}\right\}_{n=1}^{\infty}: E \rightarrow C$ be a family of relatively quasi-nonexpansive mappings and let $\left\{S_{i}\right\}_{i=1}^{N}: C \rightarrow C$ be a family of relatively quasi-nonexpansive mappings such that $F:=\bigcap_{n=1}^{\infty} F\left(T_{n}\right) \cap$ $\bigcap_{i=1}^{N} F\left(S_{i}\right) \neq \emptyset$. Let the sequence $\left\{x_{n}\right\}$ be generated by $x_{1} \in C$,

$$
x_{n+1}=T_{n} J^{-1} \sum_{i=1}^{N} \omega_{n, i}\left(\alpha_{n, i} J x_{n}+\left(1-\alpha_{n, i}\right) J S_{i} x_{n}\right)
$$

for any $n \in \mathbb{N},\left\{\omega_{n, i}\right\},\left\{\alpha_{n, i}\right\} \subset[0,1]$ for all $n \in \mathbb{N}, i=1,2, \ldots, N$ such that $\sum_{i=1}^{N} \omega_{n, i}=1$ for all $n \in \mathbb{N}$. Then $\left\{\Pi_{F} x_{n}\right\}$ converges strongly to $z \in F$, where $\Pi_{F}$ is the generalized projection of $C$ onto $F$. 
Proof. Let $u \in \bigcap_{n=1}^{\infty} F\left(T_{n}\right) \cap \bigcap_{i=1}^{N} F\left(S_{i}\right)$. Put

$$
U_{n}=T_{n} J^{-1} \sum_{i=1}^{N} \omega_{n, i}\left(\alpha_{n, i} J+\left(1-\alpha_{n, i}\right) J S_{i}\right)
$$

From Lemma 1.7, we have

$$
\phi\left(u, x_{n+1}\right)=\phi\left(u, U_{n} x_{n}\right) \leq \phi\left(u, x_{n}\right) .
$$

Therefore $\lim _{n \rightarrow \infty} \phi\left(u, x_{n}\right)$ exists. This implies that $\left\{\phi\left(u, x_{n}\right)\right\},\left\{x_{n}\right\}$ and $\left\{S_{i} x_{n}\right\}$ are bounded for all $i=1,2, \ldots, N$.

Let $y_{n} \equiv \Pi_{F} x_{n}$. From (2.3) and $m \in \mathbb{N}$, we have

$$
\phi\left(y_{n}, x_{n+m}\right) \leq \phi\left(y_{n}, x_{n}\right)
$$

Consequently,

$$
\phi\left(y_{n}, y_{n+m}\right)+\phi\left(y_{n+m}, x_{n+m}\right) \leq \phi\left(y_{n}, x_{n+m}\right) \leq \phi\left(y_{n}, x_{n}\right)
$$

In particular,

$$
\phi\left(y_{n+1}, x_{n+1}\right) \leq \phi\left(y_{n}, x_{n}\right)
$$

This implies that $\lim _{n \rightarrow \infty} \phi\left(y_{n}, x_{n}\right)$ exists. This together with the boundedness of $\left\{x_{n}\right\}$ gives $r:=\sup _{n \in \mathbb{N}}\left\|y_{n}\right\|<\infty$. Using Lemma 1.3, there exists a strictly increasing, continuous, and convex function $h:[0,2 r] \rightarrow \mathbb{R}$ such that $h(0)=0$ and

$$
h\left(\left\|y_{n}-y_{n+m}\right\|\right) \leq \phi\left(y_{n}, y_{n+m}\right) \leq \phi\left(y_{n}, x_{n}\right)-\phi\left(y_{n+m}, x_{n+m}\right) .
$$

Since $\left\{\phi\left(y_{n}, x_{n}\right)\right\}$ is a convergent sequence, it follows from the properties of $g$ that $\left\{y_{n}\right\}$ is a Cauchy sequence. Since $F$ is closed, there exists $z \in F$ such that $y_{n} \rightarrow z$.

We first establish weak convergence theorem for finding a common fixed point of a countable family of relatively quasi-nonexpansive mappings. Recall that, for a family of mappings $\left\{T_{n}\right\}_{n=1}^{\infty}: C \rightarrow E$ with $\bigcap_{n=1}^{\infty} F\left(T_{n}\right) \neq \emptyset$, we say that $\left\{T_{n}\right\}$ satisfies the NST-condition [19] if for each bounded sequence $\left\{z_{n}\right\}$ in $C$,

$$
\lim _{n \rightarrow \infty}\left\|z_{n}-T_{n} z_{n}\right\|=0 \text { implies } \omega_{w}\left\{z_{n}\right\} \subset \bigcap_{n=1}^{\infty} F\left(T_{n}\right)
$$

where $\omega_{w}\left\{z_{n}\right\}$ denotes the set of all weak subsequential limits of a sequence $\left\{z_{n}\right\}$. 
Theorem 2.2. Let $C$ be a nonempty closed convex subset of a uniformly smooth and uniformly convex Banach space $E$. Let $\left\{T_{n}\right\}_{n=1}^{\infty}: E \rightarrow C$ be a family of relatively quasi-nonexpansive mappings satisfying NST-condition and let $\left\{S_{i}\right\}_{i=1}^{N}: C \rightarrow C$ be a family of relatively nonexpansive mappings such that $F:=\bigcap_{n=1}^{\infty} F\left(T_{n}\right) \cap \bigcap_{i=1}^{N} F\left(S_{i}\right) \neq \emptyset$ and suppose that

$$
\phi\left(u, T_{n} x\right)+\phi\left(T_{n} x, x\right) \leq \phi(u, x)
$$

for all $u \in \bigcap_{n=1}^{\infty} F\left(T_{n}\right), n \in \mathbb{N}$ and $x \in E$. Let the sequence $\left\{x_{n}\right\}$ be generated by $x_{1} \in C$,

$$
x_{n+1}=T_{n} J^{-1} \sum_{i=1}^{N} \omega_{n, i}\left(\alpha_{n, i} J x_{n}+\left(1-\alpha_{n, i}\right) J S_{i} x_{n}\right)
$$

for any $n \in \mathbb{N},\left\{\omega_{n, i}\right\},\left\{\alpha_{n, i}\right\} \subset[0,1]$ for all $n \in \mathbb{N}, i=1,2, \ldots, N$ such that $\sum_{i=1}^{N} \omega_{n, i}=1$ for all $n \in \mathbb{N}, \liminf _{n \rightarrow \infty} \omega_{n, i} \alpha_{n, i}\left(1-\alpha_{n, i}\right)>0$ for all $i=1,2, \ldots, N$. If $J$ is weakly sequentially continuous, then $\left\{x_{n}\right\}$ converges weakly to $z \in F$, where $z=\lim _{n \rightarrow \infty} \Pi_{F} x_{n}$.

Proof. Let $u \in F$. From Theorem 2.1, $\lim _{n \rightarrow \infty} \phi\left(u, x_{n}\right)$ exists and hence $\left\{x_{n}\right\}$ and $\left\{S_{i} x_{n}\right\}$ are bounded for all $i=1,2, \ldots, N$. Let

$$
r=\sup _{n \in \mathbb{N}}\left\{\left\|x_{n}\right\|,\left\|S_{1} x_{n}\right\|,\left\|S_{2} x_{n}\right\|, \ldots,\left\|S_{N} x_{n}\right\|\right\}
$$

By Lemma 1.8, there exists a strictly increasing, continuous, and convex function $g^{*}$ : $[0,2 r] \rightarrow \mathbb{R}$ such that $g^{*}(0)=0$ and

$$
\sum_{i=1}^{N} \omega_{n, i} \alpha_{n, i}\left(1-\alpha_{n, i}\right) g^{*}\left(\left\|J x_{n}-J S_{i} x_{n}\right\|\right) \leq \phi\left(u, x_{n}\right)-\phi\left(u, x_{n+1}\right) .
$$

In particular, for all $i=1,2, \ldots, N$,

$$
\omega_{n, i} \alpha_{n, i}\left(1-\alpha_{n, i}\right) g^{*}\left(\left\|J x_{n}-J S_{i} x_{n}\right\|\right) \leq \phi\left(u, x_{n}\right)-\phi\left(u, x_{n+1}\right) .
$$

Hence,

$$
\sum_{n=1}^{\infty} \omega_{n, i} \alpha_{n, i}\left(1-\alpha_{n, i}\right) g^{*}\left(\left\|J x_{n}-J S_{i} x_{n}\right\|\right)<\infty
$$

for all $i=1,2, \ldots, N$. Since $\liminf _{n \rightarrow \infty} \omega_{n, i} \alpha_{n, i}\left(1-\alpha_{n, i}\right)>0$ for all $i=1,2 \ldots, N$ and the properties of $g$, we have

$$
\lim _{n \rightarrow \infty}\left\|J x_{n}-J S_{i} x_{n}\right\|=0
$$


for all $i=1,2 \ldots, N$. Since $J^{-1}$ is uniformly norm-to-norm continuous on bounded sets, we have

$$
\lim _{n \rightarrow \infty}\left\|x_{n}-S_{i} x_{n}\right\|=0
$$

for all $i=1,2 \ldots, N$. Since $\left\{x_{n}\right\}$ is bounded, there exists a subsequence $\left\{x_{n_{k}}\right\}$ of $\left\{x_{n}\right\}$ such that $x_{n_{k}} \rightarrow z \in C$. Since $S_{i}$ is relatively nonexpansive, $z \in \widehat{F}\left(S_{i}\right)=F\left(S_{i}\right)$ for all $i=1,2 \ldots, N$.

We show that $z \in \bigcap_{n=1}^{\infty} F\left(T_{n}\right)$. Let

$$
y_{n}=J^{-1} \sum_{i=1}^{N} \omega_{n, i}\left(\alpha_{n, i} J x_{n}+\left(1-\alpha_{n, i}\right) J S_{i} x_{n}\right)
$$

We note from (2.15) that

$$
\left\|\sum_{i=1}^{N} \omega_{n, i}\left(\alpha_{n, i} J x_{n}+\left(1-\alpha_{n, i}\right) J S_{i} x_{n}\right)-J x_{n}\right\| \leq \sum_{i=1}^{N} \omega_{n, i}\left(1-\alpha_{n, i}\right)\left\|J S_{i} x_{n}-J x_{n}\right\| \longrightarrow 0 .
$$

Since $J^{-1}$ is uniformly norm-to-norm continuous on bounded sets, it follows that

$$
\lim _{n \rightarrow \infty}\left\|y_{n}-x_{n}\right\|=\lim _{n \rightarrow \infty}\left\|J^{-1}\left(\sum_{i=1}^{N} \omega_{n, i}\left(\alpha_{n, i} J x_{n}+\left(1-\alpha_{n, i}\right) J S_{i} x_{n}\right)\right)-J^{-1} J x_{n}\right\|=0 .
$$

Moreover, by (2.9) and the existence of $\lim _{n \rightarrow \infty} \phi\left(u, x_{n}\right)$, we have

$$
\begin{aligned}
\phi\left(T_{n} y_{n}, y_{n}\right) & \leq \phi\left(u, y_{n}\right)-\phi\left(u, T_{n} y_{n}\right) \\
& =\phi\left(u, J^{-1} \sum_{i=1}^{N} \omega_{n, i}\left(\alpha_{n, i} J x_{n}+\left(1-\alpha_{n, i}\right) J S_{i} x_{n}\right)\right)-\phi\left(u, x_{n+1}\right) \\
& \leq \phi\left(u, x_{n}\right)-\phi\left(u, x_{n+1}\right) \longrightarrow 0 .
\end{aligned}
$$

It follows from Lemma 1.4 that $\lim _{n \rightarrow \infty}\left\|T_{n} y_{n}-y_{n}\right\|=0$. From (2.19) and $x_{n_{k}}-z$, we have $y_{n_{k}} \rightarrow z$. Since $\left\{T_{n}\right\}$ satisfies NST-condition, we have $z \in \bigcap_{n=1}^{\infty} F\left(T_{n}\right)$. Hence $z \in F$.

Let $z_{n}=\Pi_{F} x_{n}$. From Lemma 1.5 and $z \in F$, we have

$$
\left\langle z_{n_{k}}-z, J x_{n_{k}}-J z_{n_{k}}\right\rangle \geq 0
$$

From Theorem 2.1, we know that $z_{n} \rightarrow z^{\prime} \in F$. Since $J$ is weakly sequentially continuous, we have

$$
\left\langle z^{\prime}-z, J z-J z^{\prime}\right\rangle \geq 0
$$


Moreover, since $J$ is monotone,

$$
\left\langle z^{\prime}-z, J z-J z^{\prime}\right\rangle \leq 0
$$

Then

$$
\left\langle z^{\prime}-z, J z-J z^{\prime}\right\rangle=0
$$

Since $E$ is strictly convex, $z^{\prime}=z$. This implies that $\omega_{w}\left\{x_{n}\right\}=\left\{z^{\prime}\right\}$ and hence $x_{n} \rightarrow z^{\prime}=$ $\lim _{n \rightarrow \infty} \Pi_{F} x_{n}$.

We next apply our result for finding a common element of a fixed point set of a relatively nonexpansive mapping and the solution set of an equilibrium problem. This problem is extensively studied in [11,14-16]. Let $C$ be a subset of a Banach space $E$ and let $f: C \times C \rightarrow \mathbb{R}$ be a bifunction. The equilibrium problem for a bifunction $f$ is to find $x \in C$ such that $f(x, y) \geq 0$ for all $y \in C$. The set of solutions above is denoted by $\operatorname{EP}(f)$, that is

$$
x \in \operatorname{EP}(f) \text { iff } f(x, y) \geq 0 \forall y \in C .
$$

To solve the equilibrium problem, we usually assume that a bifunction $f$ satisfies the following conditions ( $C$ is closed and convex):

(A1) $f(x, x)=0$ for all $x \in C$;

(A2) $f$ is monotone, that is, $f(x, y)+f(y, x) \leq 0$, for all $x, y \in C$;

(A3) for all $x, y, z \in C, \lim \sup _{t \downarrow} f(t z+(1-t) x, y) \leq f(x, y)$;

(A4) for all $x \in C, f(x, \cdot)$ is convex and lower semicontinuous.

The following lemma gives a characterization of a solution of an equilibrium problem.

Lemma 2.3. Let $C$ be a nonempty closed convex subset of a Banach space $E$. Let $f$ be a bifunction from $C \times C \rightarrow \mathbb{R}$ satisfying (A1)-(A4). Suppose that $p \in C$. Then $p \in E P(f)$ if and only if $f(y, p) \leq 0$ for all $y \in C$.

Proof. Let $p \in \operatorname{EP}(f)$, then $f(p, y) \geq 0$ for all $y \in C$. From (A2), we get that $f(y, p) \leq-f(p, y) \leq$ 0 for all $y \in C$.

Conversely, assume that $f(y, p) \leq 0$ for all $y \in C$. For any $y \in C$, let

$$
x_{t}=t y+(1-t) p, \quad \text { for } t \in(0,1] .
$$

Then $f\left(x_{t}, p\right) \leq 0$ and hence

$$
0=f\left(x_{t}, x_{t}\right) \leq t f\left(x_{t}, y\right)+(1-t) f\left(x_{t}, p\right) \leq t f\left(x_{t}, y\right) \text {. }
$$


So $f\left(x_{t}, y\right) \geq 0$ for all $t \in(0,1]$. From (A3), we have

$$
0 \leq \limsup _{t \downarrow 0} f(t y+(1-t) p, y) \leq f(p, y) \quad \forall y \in C
$$

Hence $p \in \operatorname{EP}(f)$.

Takahashi and Zembayashi proved the following important result.

Lemma 2.4 (see [15, Lemma 2.8]). Let $C$ be a nonempty closed convex subset of a uniformly smooth, strictly convex and reflexive Banach space $E$. Let $f$ be a bifunction from $C \times C \rightarrow \mathbb{R}$ satisfying (A1)(A4). For $r>0$ and $x \in E$, define a mapping $T_{r}: E \rightarrow C$ as follows:

$$
T_{r}(x)=\left\{z \in C: f(z, y)+\frac{1}{r}\langle y-z, J z-J x\rangle \geq 0 \forall y \in C\right\}
$$

for all $x \in E$. Then, the following hold:

(1) $T_{r}$ is single-valued;

(2) $T_{r}$ is a firmly nonexpansive-type mapping [20], that is, for all $x, y \in E$

$$
\left\langle T_{r} x-T_{r} y, J T_{r} x-J T_{r} y\right\rangle \leq\left\langle T_{r} x-T_{r} y, J x-J y\right\rangle
$$

(3) $F\left(T_{r}\right)=E P(f)$;

(4) $E P(f)$ is closed and convex.

We now deduce Takahashi and Zembayashi's recent result from Theorem 2.2.

Corollary 2.5 (see [15, Theorem 4.1]). Let $C$ be a nonempty closed convex subset of a uniformly smooth and uniformly convex Banach space $E$. Let $f$ be a bifunction from $C \times C$ to $\mathbb{R}$ satisfying (A1)$(A 4)$ and let $S$ be a relatively nonexpansive mapping from $C$ into itself such that $F(S) \cap E P(f) \neq \emptyset$. Let the sequence $\left\{x_{n}\right\}$ be generated by $u_{1} \in E$,

$$
\begin{gathered}
x_{n} \in C \text { such that } f\left(x_{n}, y\right)+\frac{1}{r_{n}}\left\langle y-x_{n}, J x_{n}-J u_{n}\right\rangle \geq 0 \quad \forall y \in C, \\
u_{n+1}=J^{-1}\left(\alpha_{n} J x_{n}+\left(1-\alpha_{n}\right) J S x_{n}\right)
\end{gathered}
$$

for every $n \in \mathbb{N},\left\{\alpha_{n}\right\} \subset[0,1]$ satisfying $\liminf _{n \rightarrow \infty} \alpha_{n}\left(1-\alpha_{n}\right)>0$ and $\left\{r_{n}\right\} \subset[a, \infty)$ for some $a>0$. If $J$ is weakly sequentially continuous, then $\left\{x_{n}\right\}$ converges weakly to $z \in \Pi_{F(S) \cap E P(f)}$, where $z=\lim _{n \rightarrow \infty} \prod_{F(S) \cap E P(f)} x_{n}$. 
Proof. Put $T_{n} \equiv T_{r_{n}}$ where $T_{r_{n}}$ is defined by Lemma 2.4. Then $\bigcap_{n=1}^{\infty} F\left(T_{n}\right)=\operatorname{EP}(f)$. By reindexing the sequences $\left\{x_{n}\right\}$ and $\left\{u_{n}\right\}$ of this iteration, we can apply Theorem 2.2 by showing that the family $\left\{T_{n}\right\}$ satisfies the condition (2.9) and NST-condition. It is proved in [15, Lemma 2.9] that

$$
\phi\left(u, T_{n} x\right)+\phi\left(T_{n} x, x\right) \leq \phi(u, x) \quad \forall x \in E, u \in \bigcap_{n=1}^{\infty} F\left(T_{n}\right) .
$$

To see that $\left\{T_{n}\right\}$ satisfies NST-condition, let $\left\{z_{n}\right\}$ be a bounded sequence in $C$ such that $\lim _{n \rightarrow \infty}\left\|z_{n}-T_{n} z_{n}\right\|=0$ and $p \in \omega_{w}\left\{z_{n}\right\}$. Suppose that there exists a subsequence $\left\{z_{n_{k}}\right\}$ of $\left\{z_{n}\right\}$ such that $z_{n_{k}} \rightarrow p$. Then $T_{n_{k}} z_{n_{k}} \rightarrow p \in C$. Since $J$ is uniformly continuous on bounded sets and $r_{n_{k}} \geq a$, we have

$$
\lim _{k \rightarrow \infty} \frac{1}{r_{n_{k}}}\left\|J z_{n_{k}}-J T_{n_{k}} z_{n_{k}}\right\|=0
$$

From the definition of $T_{r_{n_{k}}}$, we have

$$
f\left(T_{n_{k}} z_{n_{k}}, y\right)+\frac{1}{r_{n_{k}}}\left\langle y-T_{n_{k}} z_{n_{k}} J T_{n_{k}} z_{n_{k}}-J z_{n_{k}}\right\rangle \geq 0 \quad \forall y \in C
$$

Since

$$
\begin{aligned}
f\left(y, T_{n_{k}} z_{n_{k}}\right) & \leq-f\left(T_{n_{k}} z_{n_{k}}, y\right) \\
& \leq \frac{1}{r_{n_{k}}}\left\langle y-T_{n_{k}} z_{n_{k}}, J T_{n_{k}} z_{n_{k}}-J z_{n_{k}}\right\rangle \\
& \leq \frac{1}{r_{n_{k}}}\left\|y-T_{n_{k}} z_{n_{k}}\right\|\left\|J T_{n_{k}} z_{n_{k}}-J z_{n_{k}}\right\|
\end{aligned}
$$

and $f$ is lower semicontinuous and convex in the second variable, we have

$$
f(y, p) \leq \liminf _{k \rightarrow \infty} f\left(y, T_{n_{k}} z_{n_{k}}\right) \leq 0 .
$$

Thus $f(y, p) \leq 0$ for all $y \in C$. From Lemma 2.3, we have $p \in \operatorname{EP}(f)$. Then $\left\{T_{n}\right\}$ satisfies the NST-condition. From Theorem 2.2 where $N=1,\left\{x_{n}\right\}$ converges weakly to $z \in F\left(T_{n}\right) \cap F(S)=$ $\mathrm{EP}(f) \cap F(S)$, where $z=\lim _{n \rightarrow \infty} \Pi_{\mathrm{EP}(f) \cap F(S)} x_{n}$.

Using the same proof as above, we have the following result. 
Corollary 2.6 (see [11, Theorem 3.5]). Let $C$ be a nonempty and closed convex subset of a uniformly convex and uniformly smooth Banach space E. Let $f$ be a bifunction from $C \times C$ to $\mathbb{R}$ satisfies (A1)$(A 4)$ and let $T, S: C \rightarrow C$ be two relatively nonexpansive mappings such that $F:=F(T) \cap F(S) \cap$ $E P(f) \neq \emptyset$. Let the sequence $\left\{x_{n}\right\}$ be generated by the following manner:

$$
\begin{gathered}
x_{n} \in C \text { such that } f\left(x_{n}, y\right)+\frac{1}{r_{n}}\left\langle y-x_{n}, J x_{n}-J u_{n}\right\rangle \geq 0 \quad \forall y \in C, \\
u_{n+1}=J^{-1}\left(\alpha_{n} J x_{n}+\beta_{n} J T x_{n}+\gamma_{n} J S x_{n}\right) \quad \forall n \geq 1 .
\end{gathered}
$$

Assume that $\left\{\alpha_{n}\right\},\left\{\beta_{n}\right\}$, and $\left\{\gamma_{n}\right\}$ are three sequences in $[0,1]$ satisfying the following restrictions:

(a) $\alpha_{n}+\beta_{n}+\gamma_{n}=1$;

(b) $\liminf _{n \rightarrow \infty} \alpha_{n} \beta_{n}>0, \liminf _{n \rightarrow \infty} \alpha_{n} \gamma_{n}>0$;

(c) $\left\{r_{n}\right\} \subset[a, \infty)$ for some $a>0$.

If $J$ is weakly sequentially continuous, then $\left\{x_{n}\right\}$ converges weakly to $z \in F$, where $z=\lim _{n \rightarrow \infty} \Pi_{F} x_{n}$.

The following result also follows from Theorem 2.2.

Corollary 2.7 (see [9, Theorem 5.3]). Let $E$ be a uniformly smooth and uniformly convex Banach space and let $C$ be a nonempty closed convex subset of $E$. Let $\left\{S_{i}\right\}_{i=1}^{N}$ be a finite family of relatively nonexpansive mappings from $C$ into itself such that $F=\bigcap_{i=1}^{N} F\left(S_{i}\right)$ is a nonempty and let $\left\{\alpha_{n, i}\right.$ : $n, i \in \mathbb{N}, 1 \leq i \leq N\} \subset[0,1]$ and $\left\{\omega_{n, i}: n, i \in \mathbb{N}, 1 \leq i \leq N\right\} \subset[0,1]$ be sequences such that $\liminf _{n \rightarrow \infty} \alpha_{n, i}\left(1-\alpha_{n, i}\right)>0$ and $\liminf _{n \rightarrow \infty} \omega_{n, i}>0$ for all $i \in\{1,2, \ldots, N\}$ and $\sum_{i=1}^{N} \omega_{n, i}=1$ for all $n \in \mathbb{N}$. Let $U_{n}$ be a sequence of mappings defined by

$$
U_{n} x=\Pi_{C} J^{-1} \sum_{i=1}^{N} \omega_{n, i}\left(\alpha_{n, i} J x+\left(1-\alpha_{n, i}\right) J S_{i} x\right)
$$

for all $x \in C$ and let the sequence $\left\{x_{n}\right\}$ be generated by $x_{1}=x \in C$ and

$$
x_{n+1}=U_{n} x_{n} \quad(n=1,2, \ldots) .
$$

Then the following hold:

(1) the sequence $\left\{x_{n}\right\}$ is bounded and each weak subsequential limit of $\left\{x_{n}\right\}$ belongs to $\bigcap_{i=1}^{N} F\left(S_{i}\right)$;

(2) if the duality mapping $J$ from $E$ into $E^{*}$ is weakly sequentially continuous, then $\left\{x_{n}\right\}$ converges weakly to the strong limit of $\left\{\Pi_{F} x_{n}\right\}$.

Proof. Since $\Pi_{C}$ is relatively nonexpansive, the family $\left\{\Pi_{C}\right\}$ satisfies the NST-condition. Moreover, $F\left(\Pi_{C}\right)=C$ and

$$
\phi\left(x, \Pi_{C} y\right)+\phi\left(\Pi_{C} y, y\right) \leq \phi(x, y) \quad \forall y \in E, x \in C .
$$

Thus the conclusions of this corollary follow. 


\section{Strong Convergence Theorem}

In this section, we prove strong convergence of an iterative sequence generated by the hybrid method in mathematical programming. We start with the following useful common tools.

Lemma 3.1. Let $C$ be a nonempty closed convex subset of a uniformly smooth and uniformly convex Banach space E. Let $\left\{T_{n}\right\}_{n=1}^{\infty}: E \rightarrow E$ and $\left\{S_{i}\right\}_{i=1}^{N}: C \rightarrow C$ be families of relatively quasinonexpansive mappings such that $F:=\bigcap_{n=1}^{\infty} F\left(T_{n}\right) \cap \bigcap_{i=1}^{N} F\left(S_{i}\right) \neq \emptyset$, and

$$
\phi\left(u, T_{n} x\right)+\phi\left(T_{n} x, x\right) \leq \phi(u, x)
$$

for all $u \in \bigcap_{n=1}^{\infty} F\left(T_{n}\right), n \in \mathbb{N}$ and $x \in E$. Let $\left\{x_{n}\right\} \subset C$ be such that $\left\{x_{n}\right\}$ and $\left\{S_{i} x_{n}\right\}$ are bounded for all $i=1,2, \ldots, N$, and

$$
\begin{gathered}
y_{n}=J^{-1} \sum_{i=1}^{N} \omega_{n, i}\left(\alpha_{n, i} J x_{n}+\left(1-\alpha_{n, i}\right) J S_{i} x_{n}\right), \\
u_{n}=T_{n} y_{n},
\end{gathered}
$$

where $\left\{\omega_{n, i}\right\},\left\{\alpha_{n, i}\right\} \subset[0,1]$ for all $n \in \mathbb{N}$ and $i=1,2, \ldots, N$ satisfy $\sum_{i=1}^{N} \omega_{n, i}=1$ for all $n \in \mathbb{N}$, $\liminf _{n \rightarrow \infty} \omega_{n, i}\left(1-\alpha_{n, i}\right)>0$ for all $i=1,2, \ldots, N$ and $\lim _{n \rightarrow \infty}\left\|x_{n}-u_{n}\right\|=0$. Then the following statements hold:

(1) $\lim _{n \rightarrow \infty}\left(\phi\left(u, x_{n}\right)-\phi\left(u, u_{n}\right)\right)=0$ for all $u \in C$,

(2) $\lim _{n \rightarrow \infty}\left\|u_{n}-y_{n}\right\|=0$,

(3) $\omega_{w}\left\{x_{n}\right\}=\omega_{w}\left\{y_{n}\right\}$,

(4) if $\lim _{n \rightarrow \infty}\left\|x_{n+1}-x_{n}\right\|=0$, then $\lim _{n \rightarrow \infty}\left\|x_{n}-S_{i} x_{n}\right\|=0$ for all $i=1,2, \ldots, N$,

(5) if $x_{n} \rightarrow z$, then $u_{n} \rightarrow z$ and $y_{n} \rightarrow z$.

Proof. (1) Since $\lim _{n \rightarrow \infty}\left\|x_{n}-u_{n}\right\|=0$ and $J$ is uniformly norm-to-norm continuous on bounded sets,

$$
\lim _{n \rightarrow \infty}\left\|J x_{n}-J u_{n}\right\|=0
$$

We note here that $\left\{u_{n}\right\}$ is also bounded. For any $u \in C$, we have

$$
\begin{aligned}
\left|\phi\left(u, x_{n}\right)-\phi\left(u, u_{n}\right)\right| & =\left|\left\|x_{n}\right\|^{2}-\left\|u_{n}\right\|^{2}-2\left\langle u, J u_{n}-J x_{n}\right\rangle\right| \\
& \leq\left|\left\|x_{n}\right\|^{2}-\|u\|^{2}\right|+2\left|\left\langle u, J u_{n}-J x_{n}\right\rangle\right| \\
& \leq\left\|x_{n}-u_{n}\right\|\left(\left\|x_{n}\right\|+\left\|u_{n}\right\|\right)+2\|u\|\left\|J u_{n}-J x_{n}\right\| \longrightarrow 0 .
\end{aligned}
$$

(2) Let $u \in F$. Using (3.1) and the relative quasi-nonexpansiveness of each $T_{n}$, we have

$$
\phi\left(u_{n}, y_{n}\right)=\phi\left(T_{n} y_{n}, y_{n}\right) \leq \phi\left(u, y_{n}\right)-\phi\left(u, T_{n} y_{n}\right) \leq \phi\left(u, x_{n}\right)-\phi\left(u, u_{n}\right) \longrightarrow 0
$$


By Lemma 1.4 and the boundedness of $\left\{u_{n}\right\}$, we have

$$
\lim _{n \rightarrow \infty}\left\|u_{n}-y_{n}\right\|=0
$$

(3) Since

$$
\left\|x_{n}-y_{n}\right\| \leq\left\|x_{n}-u_{n}\right\|+\left\|u_{n}-y_{n}\right\|=\left\|x_{n}-u_{n}\right\|+\left\|T_{n} y_{n}-y_{n}\right\| \longrightarrow 0,
$$

we have $\omega_{w}\left\{x_{n}\right\}=\omega_{w}\left\{y_{n}\right\}$.

(4) Assume that $\lim _{n \rightarrow \infty}\left\|x_{n+1}-x_{n}\right\|=0$. From $\lim _{n \rightarrow \infty}\left\|x_{n}-y_{n}\right\|=0$, we get that $\lim _{n \rightarrow \infty}\left\|x_{n+1}-y_{n}\right\|=0$. Since $J$ is uniformly norm-to-norm continuous on bounded sets, we have

$$
\lim _{n \rightarrow \infty}\left\|J x_{n+1}-J x_{n}\right\|=\lim _{n \rightarrow \infty}\left\|J x_{n+1}-J y_{n}\right\|=0
$$

So,

$$
\begin{aligned}
\left\|J x_{n+1}-J y_{n}\right\| & =\left\|J x_{n+1}-\sum_{i=1}^{N} \omega_{n, i}\left(\alpha_{n, i} J x_{n}+\left(1-\alpha_{n, i}\right) J S_{i} x_{n}\right)\right\| \\
& \geq \sum_{i=1}^{N}\left(\omega_{n, i}\left(1-\alpha_{n, i}\right)\left\|J x_{n+1}-J S_{i} x_{n}\right\|-\omega_{n, i} \alpha_{n, i}\left\|J x_{n+1}-J x_{n}\right\|\right) .
\end{aligned}
$$

From (3.8), we have

$$
\sum_{i=1}^{N} \omega_{n, i}\left(1-\alpha_{n, i}\right)\left\|J x_{n+1}-J S_{i} x_{n}\right\| \leq\left\|J x_{n+1}-J y_{n}\right\|+\sum_{i=1}^{N} \omega_{n, i} \alpha_{n, i}\left\|J x_{n+1}-J x_{n}\right\| \longrightarrow 0
$$

It follows from $\liminf \operatorname{in}_{n \rightarrow \infty} \omega_{n, i}\left(1-\alpha_{n, i}\right)>0$ for all $i=1,2, \ldots, N$ that

$$
\lim _{n \rightarrow \infty}\left\|J x_{n+1}-J S_{i} x_{n}\right\|=0
$$

for all $i=1,2, \ldots, N$. Since $J^{-1}$ is uniformly norm-to-norm continuous on bounded sets and $\lim _{n \rightarrow \infty}\left\|x_{n+1}-x_{n}\right\|=0$, we have

$$
\lim _{n \rightarrow \infty}\left\|x_{n}-S_{i} x_{n}\right\|=0
$$

for all $i=1,2, \ldots, N$, as desired.

(5) Assume that $x_{n} \rightarrow z$. From the assumption and (2), we have

$$
\lim _{n \rightarrow \infty}\left\|x_{n}-u_{n}\right\|=\lim _{n \rightarrow \infty}\left\|u_{n}-y_{n}\right\|=0 .
$$

Hence $u_{n} \rightarrow z$ and $y_{n} \rightarrow z$. 
Lemma 3.2 (see [21, Lemma 2.4]). Let $F$ be a closed convex subset of a strictly convex, smooth and reflexive Banach space $E$ satisfying Kadec-Klee property. Let $x \in E$ and $\left\{x_{n}\right\}$ be a sequence in $E$ such that $\omega_{w}\left\{x_{n}\right\} \subset F$ and $\phi\left(x_{n}, x\right) \leq \phi\left(\Pi_{F} x, x\right)$ for all $n \in \mathbb{N}$. Then $x_{n} \rightarrow z=\Pi_{F} x$.

Recall that a Banach space $E$ satisfies Kadec-Klee property if whenever $\left\{u_{n}\right\}$ is a sequence in $E$ with $x_{n} \rightarrow x$ and $\left\|x_{n}\right\| \rightarrow\|x\|$, it follows that $x_{n} \rightarrow x$.

\subsection{The CQ-Method}

Theorem 3.3. Let $C$ be a nonempty closed convex subset of a uniformly smooth and uniformly convex Banach space $E$. Let $\left\{T_{n}\right\}_{i=1}^{\infty}: E \rightarrow$ E be a family of relatively quasi-nonexpansive mappings satisfying NST-condition and let $\left\{S_{i}\right\}_{i=1}^{N}: C \rightarrow C$ be a family of relatively nonexpansive mappings such that $F:=\bigcap_{n=1}^{\infty} F\left(T_{n}\right) \cap \bigcap_{i=1}^{N} F\left(S_{i}\right) \neq \emptyset$, and

$$
\phi\left(u, T_{n} x\right)+\phi\left(T_{n} x, x\right) \leq \phi(u, x)
$$

for all $u \in \bigcap_{n=1}^{\infty} F\left(T_{n}\right), n \in \mathbb{N}$ and $x \in E$. Let the sequence $\left\{x_{n}\right\}$ be generated by

$$
\begin{gathered}
x_{1}=x \in C, \\
u_{n}=T_{n} J^{-1} \sum_{i=1}^{N} \omega_{n, i}\left(\alpha_{n, i} J x_{n}+\left(1-\alpha_{n, i}\right) J S_{i} x_{n}\right), \\
C_{n}=\left\{z \in C: \phi\left(z, u_{n}\right) \leq \phi\left(z, x_{n}\right)\right\}, \\
Q_{n}=\left\{z \in C:\left\langle x_{n}-z, J x-J x_{n}\right\rangle \geq 0\right\}, \\
x_{n+1}=\prod_{C_{n} \cap Q_{n}} x
\end{gathered}
$$

for every $n \in \mathbb{N},\left\{\omega_{n, i}\right\},\left\{\alpha_{n, i}\right\} \subset[0,1]$ for all $n \in \mathbb{N}$ and $i=1,2, \ldots, N$ satisfying $\sum_{i=1}^{N} \omega_{n, i}=1$ for all $n \in \mathbb{N}, \liminf _{n \rightarrow \infty} \omega_{n, i}\left(1-\alpha_{n, i}\right)>0$ for all $i=1,2, \ldots, N$. Then $\left\{x_{n}\right\}$ converges strongly to $\Pi_{F} x$.

Proof. The proof is broken into 4 steps.

Step 1 ( $\left\{x_{n}\right\}$ is well defined). First, we show that $C_{n} \cap Q_{n}$ is closed and convex. Clearly, $Q_{n}$ is closed and convex. Since

$$
\phi\left(z, u_{n}\right) \leq \phi\left(z, x_{n}\right) \Longleftrightarrow\left\|u_{n}\right\|^{2}-\left\|x_{n}\right\|^{2}-2\left\langle z, J u_{n}-J x_{n}\right\rangle \leq 0
$$

then $C_{n}$ is closed and convex. Thus $C_{n} \cap Q_{n}$ is closed and convex.

We next show that $F \subset C_{n} \cap Q_{n}$. Let $u \in F$. Then, from Lemma 1.7,

$$
\phi\left(u, u_{n}\right) \leq \phi\left(u, x_{n}\right)
$$

Thus $u \in C_{n}$. Hence $F \subset C_{n}$ for all $n \in \mathbb{N}$. 
Fixed Point Theory and Applications

Next, we show by induction that $F \subset C_{n} \cap Q_{n}$ for all $n \in \mathbb{N}$. Since $Q_{1}=C$, we have

$$
F \subset C_{1} \cap Q_{1} .
$$

Suppose that $F \subset C_{k} \cap Q_{k}$ for some $k \in \mathbb{N}$. From $x_{k+1}=\Pi_{C_{k} \cap Q_{k}} x \in C_{k} \cap Q_{k}$ and the definition of the generalized projection, we have

$$
\left\langle x_{k+1}-z, J x-J x_{k+1}\right\rangle \geq 0
$$

for all $z \in C_{k} \cap Q_{k}$. From $F \subset C_{k} \cap Q_{k}$,

$$
\left\langle x_{k+1}-p, J x-J x_{k+1}\right\rangle \geq 0
$$

for all $p \in F$. Hence $F \subset Q_{k+1}$, and we also have $F \subset C_{k+1} \cap Q_{k+1}$. So, we have $\emptyset \neq F \subset C_{n} \cap Q_{n}$ for all $n \in \mathbb{N}$ and hence the sequence $\left\{x_{n}\right\}$ is well defined.

Step $2\left(\omega_{w}\left\{x_{n}\right\} \subset \bigcap_{i=1}^{N} F\left(S_{i}\right)\right)$. From the definition of $Q_{n}$, we have $x_{n}=\Pi_{Q_{n}} x$. Using Lemma 1.2, we get

$$
\phi\left(x_{n}, x\right)=\phi\left(\Pi_{Q_{n}} x, x\right) \leq \phi(u, x)-\phi\left(u, \Pi_{Q_{n}} x\right) \leq \phi(u, x)
$$

for all $u \in Q_{n}$. In particular, since $x_{n+1} \in Q_{n}$ and $\Pi_{F} x \in F \subset Q_{n}$,

$$
\begin{aligned}
& \phi\left(x_{n}, x\right) \leq \phi\left(x_{n+1}, x\right), \\
& \phi\left(x_{n}, x\right) \leq \phi\left(\Pi_{F} x, x\right)
\end{aligned}
$$

for all $n \in \mathbb{N}$. This implies that $\lim _{n \rightarrow \infty} \phi\left(x_{n}, x\right)$ exists and $\left\{x_{n}\right\}$ is bounded. Moreover, from (3.21) and $x_{n+1} \in Q_{n}$,

$$
\phi\left(x_{n}, x\right) \leq \phi\left(x_{n+1}, x\right)-\phi\left(x_{n+1}, x_{n}\right) .
$$

Hence

$$
\phi\left(x_{n+1}, x_{n}\right) \leq \phi\left(x_{n+1}, x\right)-\phi\left(x_{n}, x\right) \longrightarrow 0
$$

It follows from $x_{n+1}=\Pi_{C_{n} \cap Q_{n}} x \in C_{n}$ that

$$
\phi\left(x_{n+1}, u_{n}\right) \leq \phi\left(x_{n+1}, x_{n}\right) \longrightarrow 0 .
$$

From (3.25), (3.26), and Lemma 1.4, we have

$$
\lim _{n \rightarrow \infty}\left\|x_{n+1}-x_{n}\right\|=0=\lim _{n \rightarrow \infty}\left\|x_{n+1}-u_{n}\right\| .
$$


So $\lim _{n \rightarrow \infty}\left\|x_{n}-u_{n}\right\|=0$. Using Lemma 3.1(4), we get that

$$
\lim _{n \rightarrow \infty}\left\|x_{n}-S_{i} x_{n}\right\|=0
$$

for all $i=1,2, \ldots, N$. Since each $S_{i}$ is relatively nonexpansive,

$$
\omega_{w}\left\{x_{n}\right\} \subset \bigcap_{i=1}^{N} \widehat{F}\left(S_{i}\right)=\bigcap_{i=1}^{N} F\left(S_{i}\right)
$$

Step $3\left(\omega_{w}\left\{x_{n}\right\} \subset \bigcap_{n=1}^{\infty} F\left(T_{n}\right)\right)$. Let $y_{n}=J^{-1} \sum_{i=1}^{N} \omega_{n, i}\left(\alpha_{n, i} J x_{n}+\left(1-\alpha_{n, i}\right) J S_{i} x_{n}\right)$. From Lemma 3.1(2), we have

$$
\lim _{n \rightarrow \infty}\left\|T_{n} y_{n}-y_{n}\right\|=0,
$$

and $\omega_{w}\left\{x_{n}\right\}=\omega_{w}\left\{y_{n}\right\}$. It follows from NST-condition that $\omega_{w}\left\{x_{n}\right\}=\omega_{w}\left\{y_{n}\right\} \subset \bigcap_{n=1}^{\infty} F\left(T_{n}\right)$.

Step $4\left(x_{n} \rightarrow \Pi_{F} x\right)$. From Steps 2 and 3, we have $\omega_{w}\left\{x_{n}\right\} \subset F$. The conclusion follows by Lemma 3.2 and (3.23). result.

We apply Theorem 3.3 and the proof of Corollary 2.5 and then obtain the following

Corollary 3.4. Let $C, E, f, S$ be as in Corollary 2.5. Let the sequence $\left\{x_{n}\right\}$ be generated by

$$
\begin{gathered}
x_{1}=x \in C, \\
y_{n}=J^{-1}\left(\alpha_{n} J x_{n}+\left(1-\alpha_{n}\right) J S x_{n}\right), \\
u_{n} \in C \text { such that } f\left(u_{n}, y\right)+\frac{1}{r_{n}}\left\langle y-u_{n}, J u_{n}-J y_{n}\right\rangle \geq 0 \quad \forall y \in C, \\
C_{n}=\left\{z \in C: \phi\left(z, u_{n}\right) \leq \phi\left(z, x_{n}\right)\right\}, \\
Q_{n}=\left\{z \in C:\left\langle x_{n}-z, J x-J x_{n}\right\rangle \geq 0\right\}, \\
x_{n+1}=\prod_{C_{n} \cap Q_{n}} x
\end{gathered}
$$

for every $n \in \mathbb{N},\left\{\alpha_{n}\right\} \subset[0,1]$ satisfying $\limsup _{n \rightarrow \infty} \alpha_{n}<1$ and $\left\{r_{n}\right\} \subset[a, \infty]$ for some $a>0$. Then, $\left\{x_{n}\right\}$ converges strongly to $\Pi_{F(S) \cap E P(f)} x$, where $\Pi_{F(S) \cap E P(f)}$ is the generalized projection of $E$ onto $F(S) \cap E P(f)$.

Remark 3.5. Corollary 3.4 improves the restriction on $\left\{\alpha_{n}\right\}$ of [15, Theorem 3.1]. In fact, it is assumed in [15, Theorem 3.1] that $\liminf _{n \rightarrow \infty} \alpha_{n}\left(1-\alpha_{n}\right)>0$. 


\subsection{The Monotone CQ-Method}

Let $C$ be a closed subset of a Banach space $E$. Recall that a mapping $T: C \rightarrow C$ is closed if for each $\left\{x_{n}\right\}$ in $C$, if $x_{n} \rightarrow x$ and $T x_{n} \rightarrow y$, then $T x=y$. A family of mappings $\left\{T_{n}\right\}: C \rightarrow E$ with $\bigcap_{n=1}^{\infty} F\left(T_{n}\right) \neq \emptyset$ is said to satisfy the $(*)$-condition if for each bounded sequence $\left\{z_{n}\right\}$ in $C$,

$$
\lim _{n \rightarrow \infty}\left\|z_{n}-T_{n} z_{n}\right\|=0, \quad z_{n} \longrightarrow z \text { imply } z \in \bigcap_{n=1}^{\infty} F\left(T_{n}\right)
$$

Remark 3.6. (1) If $\left\{T_{n}\right\}$ satisfies NST-condition, then $\left\{T_{n}\right\}$ satisfies $(*)$-condition.

(2) If $T_{n} \equiv T$ and $T$ is closed, then $\left\{T_{n}\right\}$ satisfies (*)-condition.

Theorem 3.7. Let $C$ be a nonempty closed convex subset of a uniformly smooth and uniformly convex Banach space $E$. Let $\left\{T_{n}\right\}_{n=1}^{\infty}: E \rightarrow E$ be a family of relatively quasi-nonexpansive mappings satisfying (*)-condition and let $\left\{S_{i}\right\}_{i=1}^{N}: C \rightarrow C$ be a family of closed relatively quasi-nonexpansive mappings such that $F:=\bigcap_{n=1}^{\infty} F\left(T_{n}\right) \cap \bigcap_{i=1}^{N} F\left(S_{i}\right) \neq \emptyset$, and

$$
\phi\left(u, T_{n} x\right)+\phi\left(T_{n} x, x\right) \leq \phi(u, x)
$$

for all $u \in \bigcap_{n=1}^{\infty} F\left(T_{n}\right), n \in \mathbb{N}$, and $x \in E$. Let the sequence $\left\{x_{n}\right\}$ be generated by

$$
\begin{gathered}
x_{0}=x \in C, \quad Q_{0}=C, \\
u_{n}=T_{n} J^{-1} \sum_{i=1}^{N} \omega_{n, i}\left(\alpha_{n, i} J x_{n}+\left(1-\alpha_{n, i}\right) J S_{i} x_{n}\right), \\
C_{0}=\left\{z \in C: \phi\left(z, u_{0}\right) \leq \phi\left(z, x_{0}\right)\right\}, \\
C_{n}=\left\{z \in C_{n-1} \cap Q_{n-1}: \phi\left(z, u_{n}\right) \leq \phi\left(z, x_{n}\right)\right\}, \\
Q_{n}=\left\{z \in C_{n-1} \cap Q_{n-1}:\left\langle x_{n}-z, J x-J x_{n}\right\rangle \geq 0\right\}, \\
x_{n+1}=\prod_{C_{n} \cap Q_{n}} x
\end{gathered}
$$

for every $n \in \mathbb{N},\left\{\omega_{n, i}\right\},\left\{\alpha_{n, i}\right\} \subset[0,1]$ satisfying $\sum_{i=1}^{N} \omega_{n, i}=1$ and $\liminf _{n \rightarrow \infty} \omega_{n, i}\left(1-\alpha_{n, i}\right)>0$ for all $i=1,2, \ldots, N$. Then $\left\{x_{n}\right\}$ converges strongly to $\Pi_{F} x$.

Proof.

Step 1 ( $\left\{x_{n}\right\}$ is well defined). This step is almost the same as Step 1 of the proof of Theorem 3.3, so it is omitted.

Step $2\left(\left\{x_{n}\right\}\right.$ is a Cauchy sequence in $\left.C\right)$. We can follow the proof of Theorem 3.3 and conclude that

$$
\lim _{n \rightarrow \infty} \phi\left(x_{n}, x\right)
$$


exists. Moreover, as $x_{n+m} \in Q_{n}$ for all $n, m$ and $x_{n}=\Pi_{Q_{n}} x$,

$$
\begin{aligned}
\phi\left(x_{n+m}, x_{n}\right) & =\phi\left(x_{n+m}, \Pi_{Q_{n}} x\right) \\
& \leq \phi\left(x_{n+m}, x\right)-\phi\left(\Pi_{Q_{n}} x, x\right) \\
& =\phi\left(x_{n+m}, x\right)-\phi\left(x_{n}, x\right) .
\end{aligned}
$$

Since $\left\{x_{n}\right\}$ is bounded, it follows from Lemma 1.3 that there exists a strictly increasing, continuous, and convex function $h$ such that $h(0)=0$ and

$$
h\left(\left\|x_{n+m}-x_{n}\right\|\right) \leq \phi\left(x_{n+m}, x\right)-\phi\left(x_{n}, x\right) .
$$

Since $\lim _{n \rightarrow \infty} \phi\left(x_{n}, x\right)$ exists, we have that $\left\{x_{n}\right\}$ is a Cauchy sequence. Therefore, $x_{n} \rightarrow z$ for some $z \in C$.

Step $3\left(z \in \bigcap_{i=1}^{N} F\left(S_{i}\right)\right)$. Since $x_{n+1}=\prod_{C_{n} \cap Q_{n}} x \in C_{n}$, we have

$$
\phi\left(x_{n+1}, u_{n}\right) \leq \phi\left(x_{n+1}, x_{n}\right) \longrightarrow \phi(z, z)=0
$$

By Lemma 1.4 and the boundedness of $\left\{x_{n}\right\}$, we have

$$
\lim _{n \rightarrow \infty}\left\|x_{n+1}-u_{n}\right\|=0
$$

So, we have $\lim _{n \rightarrow \infty}\left\|x_{n}-u_{n}\right\|=0$. Using Lemma 3.1(4), we get that

$$
\lim _{n \rightarrow \infty}\left\|x_{n}-S_{i} x_{n}\right\|=0
$$

for all $i=1,2, \ldots, N$. Since each $S_{i}$ is closed, $z \in \bigcap_{i=1}^{N} F\left(S_{i}\right)$.

Step $4\left(z \in \bigcap_{n=1}^{\infty} F\left(T_{n}\right)\right)$. Let $y_{n}=J^{-1} \sum_{i=1}^{N} \omega_{n, i}\left(\alpha_{n, i} J x_{n}+\left(1-\alpha_{n, i}\right) J S_{i} x_{n}\right)$. From Lemma 3.1(2), we have $\lim _{n \rightarrow \infty}\left\|y_{n}-T_{n} y_{n}\right\|=0$ and $y_{n} \rightarrow z$. It follows from $(*)$-condition that $z \in \bigcap_{n=1}^{\infty} F\left(T_{n}\right)$.

Step $5\left(x_{n} \rightarrow \Pi_{F} x\right)$. From Steps 3 and 4 , we have $\omega_{w}\left\{x_{n}\right\} \subset F$. The conclusion follows by Lemma 3.2 and (3.23).

Letting $T_{n}=$ identity and $S_{1}=S_{2}=\cdots=S_{N}$ yield the following result. 
Corollary 3.8 (see [12, Theorem 3.1]). Let $C$ be a nonempty closed convex subset of a uniformly convex and uniformly smooth real Banach space E. Let $T: C \rightarrow C$ be a closed relatively quasinonexpansive mapping such that $F(T) \neq \emptyset$. Assume that $\left\{\alpha_{n}\right\}$ is a sequence in $[0,1]$ such that $\limsup _{n \rightarrow \infty} \alpha_{n}<1$. Define a sequence $\left\{x_{n}\right\}$ in $C$ by the following algorithm:

$$
\begin{gathered}
x_{0} \in C \text { chosen arbitrarily, } \\
y_{n}=J^{-1}\left(\alpha_{n} J x_{n}+\left(1-\alpha_{n}\right) J T x_{n}\right), \\
C_{n}=\left\{z \in C_{n-1} \cap Q_{n-1}: \phi\left(z, y_{n}\right) \leq \phi\left(z, x_{n}\right)\right\}, \\
C_{0}=\left\{z \in C: \phi\left(z, y_{0}\right) \leq \phi\left(z, x_{0}\right)\right\}, \\
Q_{n}=\left\{z \in C_{n-1} \cap Q_{n-1}:\left\langle x_{n}-z, J x_{0}-J x_{n}\right\rangle \geq 0\right\}, \\
Q_{0}=C, \\
x_{n+1}=\prod_{C_{n} \cap Q_{n}} x_{0} .
\end{gathered}
$$

Then $\left\{x_{n}\right\}$ converges strongly to $\Pi_{F(T)} x_{0}$.

Letting $T_{n}=$ identity and $N=2$ yield the following result.

Corollary 3.9 (see [13, Theorem 3.1]). Let $C$ be a nonempty closed convex subset of a uniformly convex and uniformly smooth real Banach space $E$. Let $T, S$ be two closed relatively quasi-nonexpansive mappings from $C$ into itself such that $F:=F(T) \cap F(S) \neq \emptyset$. Define a sequence $\left\{x_{n}\right\}$ in $C$ be the following algorithm:

$$
\begin{gathered}
x_{0} \in C \text { chosen arbitrarily, } \\
z_{n}=J^{-1}\left(\beta_{n}^{(1)} J x_{n}+\beta_{n}^{(2)} J T x_{n}+\beta_{n}^{(3)} J S x_{n}\right), \\
y_{n}=J^{-1}\left(\alpha_{n} J x_{n}+\left(1-\alpha_{n}\right) J z_{n}\right), \\
C_{0}=\left\{z \in C: \phi\left(z, y_{0}\right) \leq \phi\left(z, x_{0}\right)\right\}, \\
C_{n}=\left\{z \in C_{n-1} \cap Q_{n-1}: \phi\left(z, y_{n}\right) \leq \phi\left(z, x_{n}\right)\right\}, \\
Q_{n}=\left\{z \in C_{n-1} \cap Q_{n-1}:\left\langle x_{n}-z, J x_{0}-J x_{n}\right\rangle \geq 0\right\}, \\
Q_{0}=C, \\
x_{n+1}=\prod_{C_{n} \cap Q_{n}} x_{0}
\end{gathered}
$$

with the conditions: $\beta_{n}^{(1)}, \beta_{n}^{(2)}, \beta_{n}^{(3)} \in[0,1]$ with $\beta_{n}^{(1)}+\beta_{n}^{(2)}+\beta_{n}^{(3)}=1$ and

(1) $\liminf _{n \rightarrow \infty} \beta_{n}^{(1)} \beta_{n}^{(2)}>0$;

(2) $\liminf _{n \rightarrow \infty} \beta_{n}^{(1)} \beta_{n}^{(3)}>0$;

(3) $0 \leq \alpha_{n} \leq \alpha<1$ for some $\alpha \in(0,1)$.

Then $\left\{x_{n}\right\}$ converges strongly to $\Pi_{F} x_{0}$. 
Remark 3.10. Using Theorem 3.7, we can show that the conclusion of Corollary 3.9 remains true under the more general restrictions on $\left\{\alpha_{n}\right\},\left\{\beta_{n}^{(1)}\right\},\left\{\beta_{n}^{(2)}\right\}$, and $\left\{\beta_{n}^{(3)}\right\}$ :

(1) $\alpha_{n}, \beta_{n}^{(1)} \in[0,1]$ are arbitrary;

(2) $\liminf _{n \rightarrow \infty} \beta_{n}^{(2)}>0$ and $\liminf _{n \rightarrow \infty} \beta_{n}^{(3)}>0$.

\subsection{The Shrinking Projection Method}

Theorem 3.11. Let $C, E,\left\{T_{n}\right\}_{n=1}^{\infty},\left\{S_{i}\right\}_{i=1}^{N}$ be as in Theorem 3.7. Let the sequence $\left\{x_{n}\right\}$ be generated by

$$
\begin{gathered}
x_{0} \in E \text { chosen arbitrarily, } \\
C_{1}=C, \\
x_{1}=\prod_{C_{1}} x_{0}, \\
u_{n}=T_{n} J^{-1} \sum_{i=1}^{N} \omega_{n, i}\left(\alpha_{n, i} J x_{n}+\left(1-\alpha_{n, i}\right) J S_{i} x_{n}\right), \\
C_{n+1}=\left\{z \in C_{n}: \phi\left(z, u_{n}\right) \leq \phi\left(z, x_{n}\right)\right\}, \\
x_{n+1}=\prod_{C_{n+1}} x_{0}
\end{gathered}
$$

for every $n \in \mathbb{N},\left\{\omega_{n, i}\right\},\left\{\alpha_{n, i}\right\} \subset[0,1]$ for all $n \in \mathbb{N}$ and $i=1,2, \ldots, N$ satisfies $\sum_{i=1}^{N} \omega_{n, i}=1$ for all $n \in \mathbb{N}, \liminf _{n \rightarrow \infty} \omega_{n, i}\left(1-\alpha_{n, i}\right)>0$ for all $i=1,2, \ldots, N$. Then $\left\{x_{n}\right\}$ converges strongly to $\Pi_{F} x$.

Proof. The proof is almost the same as the proofs of Theorems 3.3 and 3.7; so it is omitted.

In particular, applying Theorem 3.11 gives the following result.

Corollary 3.12. Let $C, E, f, S$ be as in Corollary 2.5. Let the sequence $\left\{x_{n}\right\}$ be generated by $x_{0}=$ $x \in C, C_{0}=C$ and

$$
\begin{gathered}
y_{n}=J^{-1}\left(\alpha_{n} J x_{n}+\left(1-\alpha_{n}\right) J S x_{n}\right), \\
u_{n} \in C \text { such that } f\left(u_{n}, y\right)+\frac{1}{r_{n}}\left\langle y-u_{n}, J u_{n}-J y_{n}\right\rangle \geq 0 \quad \forall y \in C, \\
C_{n+1}=\left\{z \in C_{n}: \phi\left(z, u_{n}\right) \leq \phi\left(z, x_{n}\right)\right\}, \\
x_{n+1}=\prod_{C_{n+1}} x_{0}
\end{gathered}
$$

for every $n \in \mathbb{N} \cup\{0\}$, where $J$ is the duality mapping on $E$. Assume that $\left\{\alpha_{n}\right\} \subset[0,1]$ satisfies $\limsup _{n \rightarrow \infty} \alpha_{n}<1$ and $\left\{r_{n}\right\} \subset[a, \infty)$ for some $a>0$. Then $\left\{x_{n}\right\}$ converges strongly to $\Pi_{F(S) \cap E P(f)} x$, where $\Pi_{F(S) \cap E P(f)}$ is the generalized projection of $E$ onto $F(S) \cap E P(f)$.

Remark 3.13. Corollary 3.12 improves the restriction on $\left\{\alpha_{n}\right\}$ of [16, Theorem 3.1]. In fact, it is assumed in [16, Theorem 3.1] that $\liminf _{n \rightarrow \infty} \alpha_{n}\left(1-\alpha_{n}\right)>0$. 
Corollary 3.14 (see [11, Theorem 3.1]). Let $C$ be a nonempty and closed convex subset of a uniformly convex and uniformly smooth Banach space E. Let $f$ be a bifunction from $C \times C$ to $\mathbb{R}$ satisfying (A1)-(A4) and let $T, S: C \rightarrow C$ be two closed relatively quasi-nonexpansive mappings such that $F:=F(T) \cap F(S) \cap E P(f) \neq \emptyset$. Let the sequence $\left\{x_{n}\right\}$ be generated by the following manner:

$$
\begin{gathered}
x_{0} \in E \text { chosen arbitrarily, } \\
C_{1}=C, \\
x_{1}=\Pi_{C_{1}} x_{0}, \\
y_{n}=J^{-1}\left(\alpha_{n} J x_{n}+\beta_{n} J T x_{n}+\gamma_{n} J S x_{n}\right), \\
u_{n} \in C \text { such that } f\left(u_{n}, y\right)+\frac{1}{r_{n}}\left\langle y-u_{n} J u_{n}-J y_{n}\right\rangle \geq 0 \quad \forall y \in C, \\
C_{n+1}=\left\{z \in C_{n}: \phi\left(z, u_{n}\right) \leq \phi\left(z, x_{n}\right)\right\}, \\
x_{n+1}=\prod_{C_{n+1}} x_{0} .
\end{gathered}
$$

Assume that $\left\{\alpha_{n}\right\},\left\{\beta_{n}\right\}$, and $\left\{\gamma_{n}\right\}$ are three sequences in $[0,1]$ satisfying the restrictions:

(a) $\alpha_{n}+\beta_{n}+\gamma_{n}=1$;

(b) $\liminf _{n \rightarrow \infty} \alpha_{n} \beta_{n}>0, \liminf _{n \rightarrow \infty} \alpha_{n} \gamma_{n}>0$;

(c) $\left\{r_{n}\right\} \subset[a, \infty)$ for some $a>0$.

Then $\left\{x_{n}\right\}$ converges strongly to $\Pi_{F} x_{0}$.

Remark 3.15. The conclusion of Corollary 3.14 remains true under the more general assumption; that is, we can replace (b) by the following one:

$\left(\mathrm{b}^{\prime}\right) \liminf _{n \rightarrow \infty} \beta_{n}>0$ and $\liminf _{n \rightarrow \infty} \gamma_{n}>0$.

We also deduce the following result.

Corollary 3.16 (see [14, Theorem 3.1]). Let C, E, f, T, S be as in Corollary 3.14. Let the sequences $\left\{x_{n}\right\},\left\{y_{n}\right\},\left\{z_{n}\right\}$, and $\left\{u_{n}\right\}$ be generated by the following:

$$
\begin{gathered}
x_{0} \in E \text { chosen arbitrarily, } \\
C_{1}=C, \\
x_{1}=\Pi_{C_{1}} x_{0}, \\
y_{n}=J^{-1}\left(\delta_{n} J x_{n}+\left(1-\delta_{n}\right) J z_{n}\right), \\
z_{n}=J^{-1}\left(\alpha_{n} J x_{n}+\beta_{n} J T x_{n}+\gamma_{n} J S x_{n}\right), \\
u_{n} \in C \text { such that } f\left(u_{n}, y\right)+\frac{1}{r_{n}}\left\langle y-u_{n}, J u_{n}-J z_{n}\right\rangle \geq 0 \quad \forall y \in C, \\
C_{n+1}=\left\{z \in C_{n}: \phi\left(z, u_{n}\right) \leq \phi\left(z, x_{n}\right)\right\}, \\
x_{n+1}=\prod_{C_{n+1}} x_{0} .
\end{gathered}
$$


Assume that $\left\{\alpha_{n}\right\},\left\{\beta_{n}\right\}$, and $\left\{\gamma_{n}\right\}$ are three sequences in $[0,1]$ satisfying the following restrictions:

(a) $\alpha_{n}+\beta_{n}+\gamma_{n}=1$;

(b) $0 \leq \alpha_{n}<1$ for all $n \in \mathbb{N} \cup\{0\}$ and $\lim _{\sup _{n \rightarrow \infty}} \alpha_{n}<1$;

(c) $\liminf _{n \rightarrow \infty} \alpha_{n} \beta_{n}>0, \liminf _{n \rightarrow \infty} \alpha_{n} \gamma_{n}>0$;

(d) $\left\{r_{n}\right\} \subset[a, \infty)$ for some $a>0$.

Then $\left\{x_{n}\right\}$ and $\left\{u_{n}\right\}$ converge strongly to $\Pi_{F} x_{0}$.

Remark 3.17. The conclusion of Corollary 3.16 remains true under the more general restrictions; that is, we replace (b) and (c) by the following one:

$\left(\mathrm{b}^{\prime}\right) \liminf _{n \rightarrow \infty} \beta_{n}>0$ and $\liminf _{n \rightarrow \infty} \gamma_{n}>0$.

Corollary 3.18 (see [10, Theorem 3.1]). Let $C$ be a nonempty closed convex subset of a uniformly convex and uniformly smooth Banach space $E$. Let $\left\{T_{i}\right\}_{i=1}^{N}: C \rightarrow C$ be a family of relatively nonexpansive mappings such that $F:=\bigcap_{i=1}^{N} F\left(T_{i}\right) \neq \emptyset$ and let $x_{0} \in E$. For $C_{1}=C$ and $x_{1}=\Pi_{C_{1}} x_{0}$, define a sequence $\left\{x_{n}\right\}$ of $C$ as follows:

$$
\begin{gathered}
y_{n}=J^{-1}\left(\alpha_{n} J x_{n}+\left(1-\alpha_{n}\right) J z_{n}\right), \\
z_{n}=J^{-1}\left(\beta_{n}^{(1)} J x_{n}+\sum_{i=1}^{N} \beta_{n}^{(i+1)} J T_{i} x_{n}\right), \\
C_{n+1}=\left\{z \in C_{n}: \phi\left(z, y_{n}\right) \leq \phi\left(z, x_{n}\right)\right\}, \\
x_{n+1}=\prod_{C_{n+1}} x_{0},
\end{gathered}
$$

where $\left\{\alpha_{n}\right\},\left\{\beta_{n}^{(i)}\right\} \subset[0,1]$ satisfies the following restrictions:

(i) $0 \leq \alpha_{n}<1$ for all $n \in \mathbb{N} \cup\{0\}$ and $\limsup _{n \rightarrow \infty} \alpha_{n}<1$;

(ii) $0 \leq \beta_{n}^{(i)} \leq 1$ for all $i=1,2, \ldots, N+1, \sum_{i=1}^{N+1} \beta_{n}^{(i)}=1$ for all $n \in \mathbb{N} \cup\{0\}$. If

(a) either $\liminf _{n \rightarrow \infty} \beta_{n}^{(1)} \beta_{n}^{(i+1)}>0$ for all $i=1,2, \ldots, N$ or

(b) $\lim _{n \rightarrow \infty} \beta_{n}^{(1)}=0$ and $\liminf _{n \rightarrow \infty} \beta_{n}^{(k+1)} \beta_{n}^{(l+1)}>0$ for all $i \neq j, k, l=1,2, \ldots, N$.

then the sequence $\left\{x_{n}\right\}$ converges strongly to $\Pi_{F} x_{0}$.

Remark 3.19. The conclusion of Corollary 3.18 remains true under the more general restrictions on $\left\{\alpha_{n}\right\},\left\{\beta_{n}^{(i)}\right\}$ :

(1) $\alpha_{n}, \beta_{n}^{(1)} \in[0,1]$ are arbitrary.

(2) $\liminf \operatorname{in}_{n \rightarrow \infty} \beta_{n}^{(i)}>0$ for all $i=2, \ldots, N$. 


\section{Acknowledgments}

The authors would like to thank the referee for their comments on the manuscript. The first author is supported by grant fund under the program Strategic Scholarships for Frontier Research Network for the Ph.D. Program Thai Doctoral degree from the Office of the Higher Education Commission, Thailand, and the second author is supported by the Thailand Research Fund under Grant MRG5180146.

\section{References}

[1] S.-Y. Matsushita and W. Takahashi, "Weak and strong convergence theorems for relatively nonexpansive mappings in Banach spaces," Fixed Point Theory and Applications, vol. 2004, no. 1, pp. 37-47, 2004.

[2] Y. I. Alber, "Metric and generalized projection operators in Banach spaces: properties and applications," in Theory and Applications of Nonlinear Operators of Accretive and Monotone Type, vol. 178 of Lecture Notes in Pure and Applied Mathematics, pp. 15-50, Marcel Dekker, New York, NY, USA, 1996.

[3] W. Takahashi, Convex Analysis and Approximation Fixed points, vol. 2 of Mathematical Analysis Series, Yokohama Publishers, Yokohama, Japan, 2000.

[4] W. Takahashi, Nonlinear Functional Analysis, Fixed Point Theory and Its Application, Yokohama Publishers, Yokohama, Japan, 2000.

[5] I. Cioranescu, Geometry of Banach Spaces, Duality Mappings and Nonlinear Problems, vol. 62 of Mathematics and Its Applications, Kluwer Academic Publishers, Dordrecht, The Netherlands, 1990.

[6] S. Matsushita and W. Takahashi, "A strong convergence theorem for relatively nonexpansive mappings in a Banach space," Journal of Approximation Theory, vol. 134, no. 2, pp. 257-266, 2005.

[7] W. Nilsrakoo and S. Saejung, "Strong convergence to common fixed points of countable relatively quasi-nonexpansive mappings," Fixed Point Theory and Applications, vol. 2008, Article ID 312454, 19 pages, 2008.

[8] S. Reich, "A weak convergence theorem for the alternating method with Bregman distances," in Theory and Applications of Nonlinear Operators of Accretive and Monotone Type, vol. 178 of Lecture Notes in Pure and Applied Mathematics, pp. 313-318, Marcel Dekker, New York, NY, USA, 1996.

[9] F. Kohsaka and W. Takahashi, "Block iterative methods for a finite family of relatively nonexpansive mappings in Banach spaces," Fixed Point Theory and Applications, vol. 2007, Article ID 21972, 18 pages, 2007.

[10] S. Plubtieng and K. Ungchittrakool, "Hybrid iterative methods for convex feasibility problems and fixed point problems of relatively nonexpansive mappings in Banach spaces," Fixed Point Theory and Applications, vol. 2008, Article ID 583082, 19 pages, 2008.

[11] X. Qin, Y. J. Cho, and S. M. Kang, "Convergence theorems of common elements for equilibrium problems and fixed point problems in Banach spaces," Journal of Computational and Applied Mathematics, vol. 225, no. 1, pp. 20-30, 2009.

[12] Y. Su, D. Wang, and M. Shang, "Strong convergence of monotone hybrid algorithm for hemi-relatively nonexpansive mappings," Fixed Point Theory and Applications, vol. 2008, Article ID 284613, 8 pages, 2008.

[13] Y. Su and H. Xu, "Strong convergence theorems for a common fixed point of two hemi-relatively nonexpansive mappings," Nonlinear Analysis: Theory, Methods E Applications, vol. 71, no. 11, pp. 56165628, 2009.

[14] K. Wattanawitoon and P. Kumam, "Strong convergence theorems by a new hybrid projection algorithm for fixed point problems and equilibrium problems of two relatively quasi-nonexpansive mappings," Nonlinear Analysis: Hybrid Systems, vol. 3, no. 1, pp. 11-20, 2009.

[15] W. Takahashi and K. Zembayashi, "Strong and weak convergence theorems for equilibrium problems and relatively nonexpansive mappings in Banach spaces," Nonlinear Analysis: Theory, Methods $\mathcal{E}$ Applications, vol. 70, no. 1, pp. 45-57, 2009.

[16] W. Takahashi and K. Zembayashi, "Strong convergence theorem by a new hybrid method for equilibrium problems and relatively nonexpansive mappings," Fixed Point Theory and Applications, vol. 2008, Article ID 528476, 11 pages, 2008. 
[17] S. Kamimura and W. Takahashi, "Strong convergence of a proximal-type algorithm in a Banach space," SIAM Journal on Optimization, vol. 13, no. 3, pp. 938-945, 2002.

[18] H. K. Xu, "Inequalities in Banach spaces with applications," Nonlinear Analysis: Theory, Methods $\mathcal{E}$ Applications, vol. 16, no. 12, pp. 1127-1138, 1991.

[19] K. Nakajo, K. Shimoji, and W. Takahashi, "Strong convergence theorems by the hybrid method for families of nonexpansive mappings in Hilbert spaces," Taiwanese Journal of Mathematics, vol. 10, no. 2, pp. 339-360, 2006.

[20] F. Kohsaka and W. Takahashi, "Existence and approximation of fixed points of firmly nonexpansivetype mappings in Banach spaces," SIAM Journal on Optimization, vol. 19, no. 2, pp. 824-835, 2008.

[21] T.-H. Kim and H.-J. Lee, "Strong convergence of modified iteration processes for relatively nonexpansive mappings," Kyungpook Mathematical Journal, vol. 48, no. 4, pp. 685-703, 2008. 